\title{
Three-Dimensional Game-Based Cardiopulmonary Bypass Training
}

\author{
Núria Bonet, $\mathrm{MS}^{\mathrm{a}}$, Ariel von Barnekow, $\mathrm{MS}^{\mathrm{a}}$, Maria Teresa Mata, MD ${ }^{\mathrm{b}, \mathrm{c}}$, \\ Carmen Gomar, PhD', Dani Tost, PhD $^{\mathrm{a}, \mathrm{d}, *}$
}

${ }^{a}$ Research Center in Biomedical Engineering (CREB), Technical University of Catalonia, Barcelona, Spain

${ }^{b}$ Hospital Clínic de Barcelona, Barcelona, Spain

${ }^{c}$ School of Medicine, University of Barcelona, Barcelona, Spain

${ }^{d}$ Research Center in Biomedical Engineering (CREB), Technical University of Catalonia, Institut de Recerca San Joan de Déu (IRSJD), Barcelona, Spain

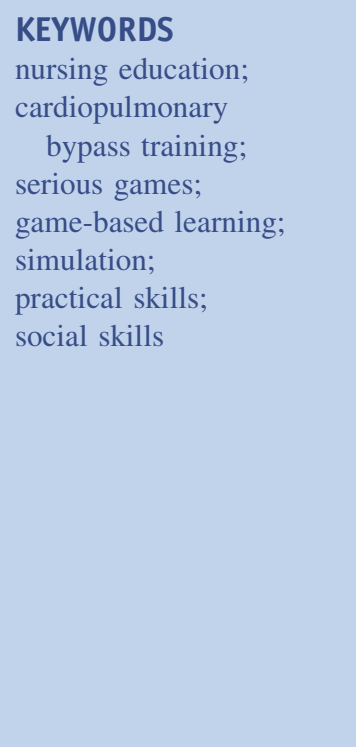

\begin{abstract}
Background: Cardiopulmonary bypass is a specialized technique requiring high technical skills and generic competencies.

Methods: The Virtual Perfusionist is a 3-dimensional serious game for training nurses in cardiopulmonary bypass management. The game design and the results of a preliminary usability analysis with a group of 28 perfusion nurse students are described. The games played, the errors, and their causes are analyzed. Students' opinions are measured with an extended System Usability Scale.

Results: The game was well praised by attendees who could complete the learning objectives after a short period of familiarization with the technology.

Conclusions: The game was found useable and satisfying. Further studies will analyze its effectiveness in cardiovascular perfusion education.

Cite this article:

Bonet, N., von Barnekow, A., Mata, M. T., Gomar, C., \& Tost, D. (2021, January). Three-dimensional game-based cardiopulmonary bypass training. Clinical Simulation in Nursing, 50(C), 81-11. https:// doi.org/10.1016/j.ecns.2020.08.007.

(C) 2020 International Nursing Association for Clinical Simulation and Learning. Published by Elsevier Inc. All rights reserved.
\end{abstract}

Perfusionist nurses play a vital role in cardiac surgery teams. They operate the cardiopulmonary bypass (CPB) machine (heart-lung machine) that provides extracorporeal blood circulation during cardiac surgery. They are responsible for blood flow and regulation of the levels of oxygen, carbon dioxide, $\mathrm{pH}$, and electrolytes, and therefore, they are continuously evaluating visual input from patient monitors

\footnotetext{
* Corresponding author: dani@cs.upc.edu (D. Tost).
}

and heart-lung machine consoles. In addition, they administer intravenous drugs and operate ancillary devices. Perfusion safety has been a major concern in literature (Stammers \& Mejak, 2001), and many technological improvements have been designed in the last years to reduce risks of accidents by increasing automation and computer assistance (Brolhorst, Peterson, \& Holt, 2019). However, the knowledge and expertise of perfusionists remain the primary factor of safety (Palanzo, 2005). 
In general, perfusion training is a two-year nursery master degree. Current curricula include theoretical lessons and clinical practices generally based on the "see one, do one, teach one" Halstedian approach (Cameron, 1997). As pointed out by Gonzalez and Kardong-Edgren (Gonzalez \& Kardong-

\section{Key Points} sionist is a $3 \mathrm{D}$ serious game intended for training nurses on technical and communication skills during perfusion. It aims at providing an immersive, challenging, and fun educational experience.

- The computational simulation model of the game provides means of creating a variety of scenarios with different levels of difficulty.

- A pilot study on the game usability shows that students and instructors find it a motivating and satisfying way of training.
- The Virtual Perfu-

Edgren, 2017), the myriad of skills taught in nursing are often very quickly forgotten. Therefore, more and more, there is an interest in the academic community to substitute passive knowledge acquisition by deliberate practice and mastery learning. In the last decade, the use of physical simulators has become popular. With these simulators, perfusionists practice a variety of clinical situations in actual operating theaters or within specialized simulation facilities. Physical simulators provide means of practical skills observational assessment. An example of a physical simulator is Orpheus (Morris \& Pybus, 2007) that has been used to train extracorporeal blood circulation techniques such as $\mathrm{CPB}$ and extracorporeal membrane oxygenation (Landsdowne, Machin, \& Grant, 2012). A randomized controlled trial has shown that simulation-based extracorporeal membrane oxygenation training is superior to traditional training for novice critical care fellows (Zakhary et al., 2017).

Computer-based simulations are a cheaper and ubiquitous way of training (Wayne et al., 2005). They can improve the achievement of learning goals and outcomes with better results than problem-based approaches (Fisher et al., 2018; Steadman et al., 2006). Moreover, used before mannequinbased training, computer simulations yield better learning and increase students' confidence (Curtin, Finn, Czosnowski, Whitman, \& Cawley, 2011). Some computer simulators exist for training extracorporeal blood circulation, for instance ECMOjo (Alsalemi et al., 2020), but they focus on extracorporeal membrane oxygenation and not on CPB.

Serious games are games, generally digital games, designed for a primary purpose other than pure leisure (Zyda, 2005). They are used in a diversity of applications and in particular in medical education. In this latter field, in an attempt to foster engagement and fun, a category of serious games called serious simulation games adds gamification elements to computerized simulations of a clinical procedure (Graafland \& Schijven, 2018). These serious games include leisure game design elements such as points, awards, badges, and game mechanics that define the rules for scoring, winning, and losing. They provide realistic simulated environments often based on 3dimensional (3D) virtual reality where players can role play as if they were in the real world but without fear of the consequences of their errors (Graafland, Schraagen, \& Schijven, 2012). These games bring an opportunity to practice in a challenging way, skills such as problem-solving, analysis, team building, and other social abilities often relegated in traditional teaching methods (Ewertsson, BaggaGupta, \& Blomberg, 2017). By opposite to physical simulators, digital serious games are purely software tools, and thus, they can be played as many times as individually needed and from everywhere. Moreover, technology provides means of registering the game play, so they are reproducible and can serve as a basis for debriefing and automatic assessment of students (Bedwell et al., 2012).

In spite of their potential advantages, the use of serious simulation games is not generalized in nursing curricula (Pront, Müller, Koschade, \& Hutton, 2018). This can be partly explained by the relative novelty of this type of technology. In addition, considerable effort and the contribution of different professional profiles are required to develop these games (Johnsen, Fossum, Vivekananda-Schmidt, Fruhling, \& Sletteb $\varnothing, 2018)$. Furthermore, as for other information technology tools, the adoption of serious games depend on individual user acceptance and organizations' intentions to use them (Venkatesh, Thong, \& Xu, 2016). Thus, scientific evidence on their usability and their effectiveness as pedagogical tools (Gentry et al., 2019) are needed.

In this article, we present the Virtual Perfusionist, a 3D serious simulation game to train nurses in the management of the CPB. The game addresses technical competencies and communication skills that are extremely important to avoid errors in the operating room (Hicks et al., 2011). We describe the game concept design and the implemented physiological simulation model. In addition, we present the results of a preliminary game usability study performed with 28 nurses at the professionalizing master in perfusion of the Hospital Clínic of the University of Barcelona, a master certified as official training by the European Board of Perfusion.

\section{The Game}

\section{Learning Objectives}

The learning objectives of the game are two-fold. First, the game is aimed at acquiring and deepening technical skills in the management of the CPB in regular conditions and critical scenarios. Second, it is intended to improve communication skills: follow verbal orders, answer 
appropriately, inform and share concerns whenever needed. The overall goal is to increase knowledge, capacity, confidence, and comfort in CPB management.

\section{Description}

The game scenario reproduces a 3D operating room and different virtual characters working in it: surgeons, anesthesiologists, nurses, and the patient (see Figure 1). The behavior of all characters is driven by the game, except the role of perfusionist nurse, which is controlled by the player. The game is presented in a first-person perspective with the virtual camera located at the position of the perfusionist sitting in front of the heart-lung machine. The player can move the view, but for simplicity, she/he is not able to virtually navigate through the environment. The system simulates the heart-lung machine including four rolling pumps (arterial, cardioplegia, vent, and suction), the venous reservoir, the oxygenator with the gas mixer, the heatercooler unit, different monitors, and accessories such as clamps, drugs, serum, and blood. The goal of the game is to manage the heart-lung machine and ancillary devices during different types of cardiac surgery keeping the patient variables within predefined ranges. In addition, throughout all the intervention, the player must communicate efficiently with the virtual team through the interface.

As an example of narrative, in a tricuspid valve repair surgery without incidents, the game starts with the pump already mounted, the patient anesthetized and having received heparin. The player must wait until the patient is well heparinized. Then, following surgeon's indications, the player starts the pump on, unclamping progressively the arterial line. The player regulates the blood flow with the arterial pump and the oxygen concentration and gas flow with the gas blender. The player must check the hematocrit and, if needed, add either blood or serum. After checking if the patient's oxygen saturation is correct, the surgeon clamps the aorta, and the player starts cardioplegia. The surgery proceeds with the surgeon asking eventually for more cardioplegia doses and the player checking the patient's variables. At the end of the surgery and again following instructions, the player administers warm cardioplegia. Next, in the CPB weaning stage, the surgeon removes the aortic clamp, and when the patient is hemodynamically stable, the player starts weaning the pump carefully by progressively clamping the venous line and reducing the flow.

In addition to the basic narrative, several incidents have been implemented to train students to manage critical situations (see Table 1). These incidents have been chosen among the recurrent ones related to the management of the CPB (Gomar, Mata, \& Pomar, 2012; Hicks et al., 2011). They have been classified as per their level of difficulty. Therefore, the game is made of different exercises (tasks) with progressively complex combinations of incidents. The cognitive load required at each level is paced not to overwhelm students (Reedy, 2015).

\section{Scoring}

The game rules for scoring have been established to implement the pedagogic model designed by the perfusion teachers that are members of the team. This model takes into account technical competencies and communication skills. Players start with a score of 100 and eventually lose points during the virtual surgical procedure depending on their errors. There are two types of errors: direct errors that are related to explicit actions or omissions of the player (see Table 2) and indirect errors that occur when the virtual

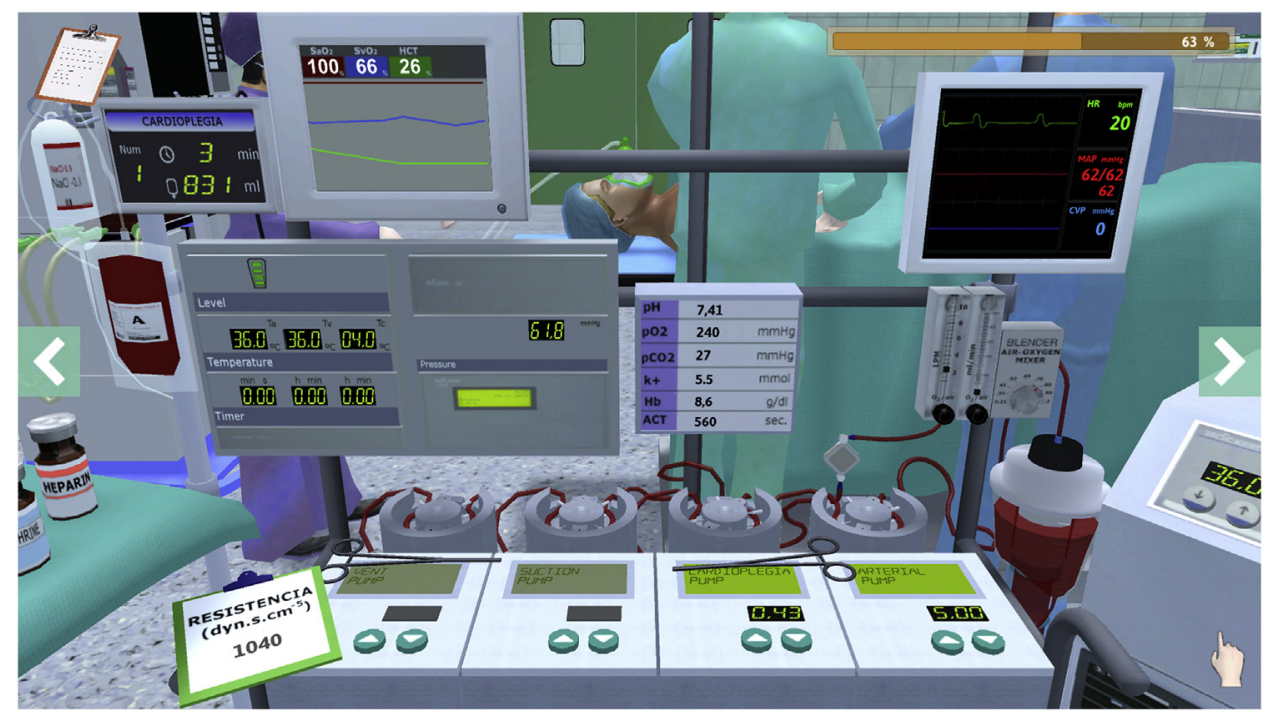

Figure 1 View of the game as seen by the player. 


\begin{tabular}{|c|c|c|c|}
\hline Task & Level & Contents & Expected Solution \\
\hline 1 & Easy & Regular surgery with no incidents & - \\
\hline 2 & Medium & During cardioplegia, the ACT decreases abruptly & The player puts more heparin \\
\hline 3 & Medium & $\begin{array}{l}\text { During cardioplegia, the venous reservoir blood level } \\
\text { lowers abruptly }\end{array}$ & $\begin{array}{l}\text { The player notifies the situation and immediately } \\
\text { reduces the pump flow. She/he asks the surgeon } \\
\text { about cannulas. When the surgeon modifies them } \\
\text { the problem is solved }\end{array}$ \\
\hline 4 & Medium & The Sv02 decreases suddenly & $\begin{array}{l}\text { The player raises the pump flow and the oxygen } \\
\text { concentration of the oxygenator gas mixer. If the } \\
\text { problem persists, she/he reduces the temperature } \\
\text { of the arterial line. }\end{array}$ \\
\hline 5 & Medium & $\begin{array}{l}\text { The MAP decreases suddenly without the player } \\
\text { having changed the speed of the pump }\end{array}$ & $\begin{array}{l}\text { The player checks the patient's systemic resistances } \\
\text { and observes that they are low, so she/he } \\
\text { administers a vasoconstrictor drug dose } \\
\text { (Phenylephrine) }\end{array}$ \\
\hline 6 & Medium & $\begin{array}{l}\text { The MAP increases suddenly without the player } \\
\text { having changed the speed of the pump }\end{array}$ & $\begin{array}{l}\text { The player checks the patient's systemic resistances } \\
\text { and observes that they are high, so she/he } \\
\text { administers a vasodilator drug dose (Urapidil or } \\
\text { Nitroprusside) }\end{array}$ \\
\hline 7 & High & A combination of two of the incidents & Solution of each incident \\
\hline
\end{tabular}

patient constants are out of the range of normality. In both cases, the amount of points withdrawn depends on the gravity of the situation. To foster a better comprehension of the situation, whenever an anomalous situation is detected, the game gives a warning alert message. After a delay, some points are withdrawn. If the error persists, the level of alert increases, a second warning is given and more points are removed.

\section{The Patient-CPB Model}

A computational model simulating the patient's physiological behavior has been implemented on the basis of state-ofthe-art extracorporeal circulation theory (Bauernschmitt et al., 1999; Gomar, Mata, \& Pomar, 2012). All variables are listed in Appendix A. The patient's age, gender, weight, height, and baseline hemoglobin level are set at the beginning of each game within established normality ranges. Table 3 shows how game actions affect these variables.

\section{Implementation}

A simplified architecture of the system is presented in Figure 2. The game is composed of four main components (orange blocks): the game rules, the game narrative, the computational model simulating the behavior of the patient connected to the heart-lung machine, and the graphical model. In run time, the game processes the narrative thread (story) along time. The story represents the events of a cardiac surgery. Changes in the computational model of the patient are programmed accordingly to the procedure and reflected in the graphical model monitors. Meanwhile, the player interacts with the components of the graphical model that receive input, namely pumps, the heater-cooler unit, the oxygenator gas mixer, clamps, drugs, blood, and serum. These interactions are processed, and the computational model variables change accordingly. The narrative thread also includes dialogues that the player is challenged with. Using the dialogue interface, the player must answer the questions asked by the virtual characters as they appear in the screen and communicate information whenever the situation requires it. Finally, during game processing, game rules are applied to score the game depending on the player's actions and the values of the patient's computational model variables.

\section{Usability Evaluation}

During the development of the game and following the principles of user-centric design, the game was periodically tested by small groups of four to six perfusionist nurses. Then, the preliminary evaluation of the game usability described as follows was held. Of the three main aspects of usability - to be useful, useable and satisfying (Zhang et al., 2011) - we addressed only being useable and satisfying. The effectiveness of the game in comparison with other learning methods is out of the scope of this study.

\section{Participants}

A group of 28 nurse students of the first course of the professionalizing master in perfusion of the University of Barcelona were recruited. All of them were volunteers. The session was approved by the academic board of the master. The group was composed of 18 women and 10 men aged between 27 and 53 (average 37.64, $\sigma=7.22$ ) years. Of 
Table 2 Training Direct Errors and Severity Level

\begin{tabular}{|c|c|c|c|c|}
\hline Skill & Description & & & Type of Error \\
\hline \multirow[t]{5}{*}{ Technical } & $\begin{array}{l}\text { Following specific surgeon's instructions } \\
\text { (e.g., to administer cardioplegia) }\end{array}$ & & Not doing it & Low \\
\hline & Not doing it after one warning & Medium & & \\
\hline & Not doing it after two warnings & Fatal & & \\
\hline & $\begin{array}{l}\text { Performing an action that requires a previous requirement } \\
\text { without having received the corresponding instruction } \\
\text { (e.g., turning the pump on before the surgeon } \\
\text { has told to do) }\end{array}$ & & & Fatal \\
\hline & $\begin{array}{l}\text { Performing actions that do not require any instruction } \\
\text { (e.g., lowing or raising the arterial pump) }\end{array}$ & & & No error \\
\hline \multirow[t]{11}{*}{ Communication } & \multirow{4}{*}{$\begin{array}{l}\text { Asking a question or giving information about the current } \\
\text { state of perfusion }\end{array}$} & \multirow{3}{*}{$\begin{array}{l}\text { Relevant information } \\
\text { (e.g., notifying that the } \\
\text { blood reservoir level is } \\
\text { low) }\end{array}$} & Not notifying & Low \\
\hline & & & $\begin{array}{l}\text { Not notifying after one } \\
\text { warning }\end{array}$ & Medium \\
\hline & & & $\begin{array}{l}\text { Not notifying after two } \\
\text { warnings }\end{array}$ & Fatal \\
\hline & & $\begin{array}{l}\text { Less relevant information } \\
\text { (e.g., confirm that } \\
\text { cardioplegia has started } \\
\text { following the surgeon } \\
\text { instructions) }\end{array}$ & Not notifying & Low \\
\hline & \multirow{7}{*}{$\begin{array}{l}\text { Answering a question asked by the surgeon or the } \\
\text { anesthesiologist }\end{array}$} & \multirow{4}{*}{$\begin{array}{l}\text { Important question (e.g., } \\
\text { question about the } \\
\text { current state of the } \\
\text { patient's saturations) }\end{array}$} & Giving an erroneous answer & Fatal \\
\hline & & & Not answering it & Low \\
\hline & & & $\begin{array}{l}\text { Not answering it after it has } \\
\text { been asked } 2 \text { times }\end{array}$ & Medium \\
\hline & & & $\begin{array}{l}\text { Not answering it after it has } \\
\text { been asked } 3 \text { times }\end{array}$ & Fatal \\
\hline & & \multirow{3}{*}{$\begin{array}{l}\text { Less important question } \\
\text { (e.g., question about } \\
\text { the age of the patient) }\end{array}$} & Giving an erroneous answer & Medium \\
\hline & & & $\begin{array}{l}\text { Not answering it after it has } \\
\text { been asked } 2 \text { times }\end{array}$ & Low \\
\hline & & & $\begin{array}{l}\text { Not answering it after it has } \\
\text { been asked } 3 \text { times }\end{array}$ & Medium \\
\hline
\end{tabular}


Table 3 Game Actions Caused by Both the Player and the Game System and the Variables They Affects (See Appendix A for the Abbreviations)

\begin{tabular}{|c|c|c|c|}
\hline Author & Game Actions & Affected Machine Variables & Affected Patient Variables \\
\hline \multirow[t]{12}{*}{ Player } & $\begin{array}{l}\text { Raise or lower the arterial flow rate by } \\
\text { clicking on the arterial pump button }\end{array}$ & Qa, BloodLevel & $\mathrm{Pa}, \mathrm{MAP}, \mathrm{Sa} 02, \mathrm{~Sv} 02, \mathrm{p} 02, \mathrm{pCO} 2$ \\
\hline & $\begin{array}{l}\text { Raise or lower the vent flow rate by } \\
\text { clicking on the vent pump button }\end{array}$ & Qvent & LVBloodLevel \\
\hline & $\begin{array}{l}\text { Raise or lower the suction flow rate by } \\
\text { clicking on the suction pump button }\end{array}$ & Qsuction & CBloodLevel \\
\hline & $\begin{array}{l}\text { Raise or lower the cardioplegia flow } \\
\text { rate by clicking on the cardioplegia } \\
\text { pump button }\end{array}$ & Qcardio & HR \\
\hline & $\begin{array}{l}\text { Raise or lower the flow rate of the gas } \\
\text { mixture by clicking on the flow rate } \\
\text { wheel of the oxygenator gas mixer }\end{array}$ & Qgas & $\mathrm{D} 02, \mathrm{Sa} 02, \mathrm{~Sv} 02, \mathrm{p} 02, \mathrm{pCO} 2$ \\
\hline & $\begin{array}{l}\text { Raise or lower the oxygen } \\
\text { concentration of the gas mixture by } \\
\text { clicking on the oxygen concentration } \\
\text { wheel of the oxygenator gas mixer }\end{array}$ & $\mathrm{FiO2}$ & $\mathrm{D} 02, \mathrm{Sa} 02, \mathrm{~Sv} 02, \mathrm{p} 02, \mathrm{pCO} 2$ \\
\hline & $\begin{array}{l}\text { Raise or lower the arterial line } \\
\text { temperature by clicking on the } \\
\text { oxygenator line button on the } \\
\text { heater-cooler exchanger }\end{array}$ & $\mathrm{T}$ & $\begin{array}{l}\text { Ta, Tv, } \eta, \text { SVR, V02, Sv02, p02, pC02, } \\
\text { pH }\end{array}$ \\
\hline & $\begin{array}{l}\text { Administer heparin by clicking on the } \\
\text { bottle of heparin on the table }\end{array}$ & - & ACT \\
\hline & $\begin{array}{l}\text { Administer a vasoconstrictor drug by } \\
\text { clicking on the bottle of } \\
\text { Phenylephrine on the table }\end{array}$ & - & SVR \\
\hline & $\begin{array}{l}\text { Administer a vasodilator drug by } \\
\text { clicking on the bottle of Urapidil on } \\
\text { the table }\end{array}$ & - & SVR \\
\hline & $\begin{array}{l}\text { Administer blood by clicking on the } \\
\text { blood bag on the serum holder }\end{array}$ & - & HCT, total_volume \\
\hline & $\begin{array}{l}\text { Administer serum by clicking on the } \\
\text { serum bag on the serum holder }\end{array}$ & - & HCT, total_volume \\
\hline \multirow[t]{4}{*}{ Game system } & $\begin{array}{l}\text { Simulate a problem with the cannulas } \\
\text { of the patient's heart (decrease the } \\
\text { level of blood in the venous } \\
\text { reservoir) }\end{array}$ & BloodLevel & - \\
\hline & $\begin{array}{l}\text { Increase in the patient's oxygen } \\
\text { consumption }\end{array}$ & - & V02, Sv02 \\
\hline & $\begin{array}{l}\text { Simulate a decrease in the effect of } \\
\text { heparin on the patient (decrease the } \\
\text { activated clotting time) }\end{array}$ & - & ACT \\
\hline & $\begin{array}{l}\text { Simulate a vasodilation or a } \\
\text { vasoconstriction of the patient's } \\
\text { blood vessels (raise or lower the } \\
\text { patient's systemic vascular } \\
\text { resistance) }\end{array}$ & - & SVR, MAP \\
\hline
\end{tabular}

them, $44 \%$ of women and $30 \%$ of men had some previous experience in clinical perfusion. Their experience ranged from 0 to 1.5 years (average $0.23, \sigma=0.37$ ). Only 4 of $28(14 \%)$ nurse students considered themselves as regular video game players (between 1.5 and 7 hours a week). Three of them declared playing 2-dimensional games (language and puzzles games) and one of them a 3D shooting role-play game.

\section{Development of the Session}

The session was held in a computer laboratory room with each student working alone. The session was guided by four facilitators following the INACSL Standards of Best Practices (INACSL, 2016). At the beginning, a brief explanation about the purpose and goals of the project was given. Students were informed that the data generated by them 


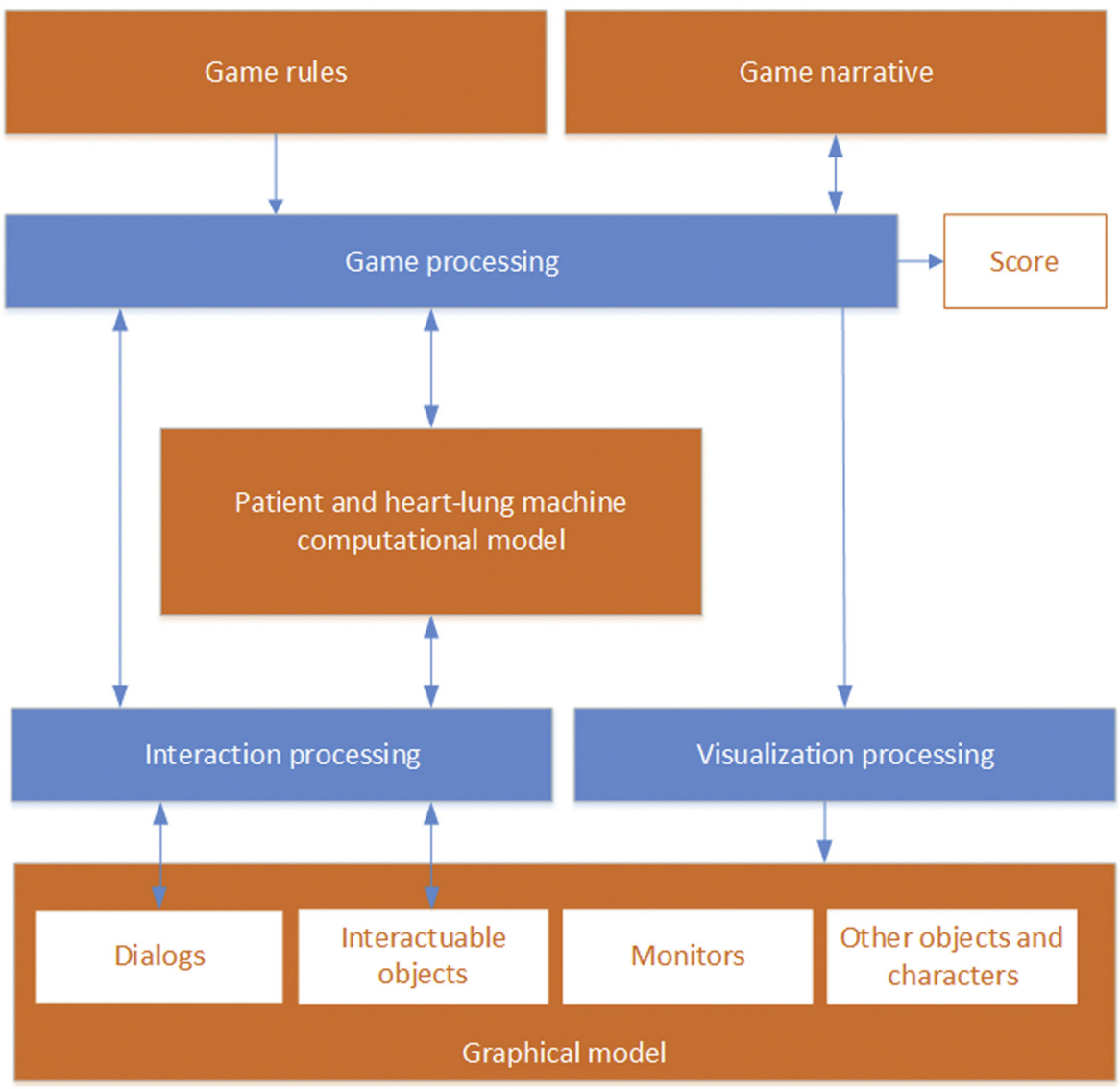

Figure 2 Architecture of the game system.

would be analyzed and that no private information (names or e-mails) would be stored or used. No formal written consent was required.

Students could choose between four tasks (tasks 1, 3, 4, and 7 from Table 1) and started to play on their own without any further explanation. They could ask for assistance when needed. They could play as many times as wanted during a time interval of 1 hour. All results were automatically registered while they were playing. All user interactions were recorded. At the end of the session, students answered a questionnaire. Finally, a debriefing debate was carried on. Students who asked for it were allowed to continue playing at home for 1 week.

\section{Variables}

To assess if the game was useable, we took as primary variables the number of games, their duration, the percentage of won games, the number of games needed before the

Table 4 Descriptive Statistical Values About the Intensity and Results of the Training

\begin{tabular}{lll}
\hline Abbr & Description & Mean (Min-Max) SD \\
\hline NPS & Number of games played per student & $12,04(7-21) \sigma=3.98$ \\
NPSS & Number of games played per student during the one hour session & $10.46(6-19) \sigma=2.80$ \\
D & Duration of each game (seconds) & $281.92(158.63-403.72) \sigma=51.78$ \\
DW & Duration of won games (seconds) & $384.20(326.73-576.92) \sigma=52.95$ \\
PWS & Percentage of games won per student & $40.92 \%(9.52 \%-61.54 \%) \sigma=14.19 \%$ \\
NPbef & Number of games needed before the first win & $4.33(1-11) \sigma=2.32$ \\
PPaft & Percentage of games played after the first win, in relation to the total & $52.37 \%(9.52 \%-80 \%) \sigma=15.95 \%$ \\
& number of games played per student & $61.80 \%(14.29 \%-100 \%) \sigma=21.07 \%$ \\
\end{tabular}




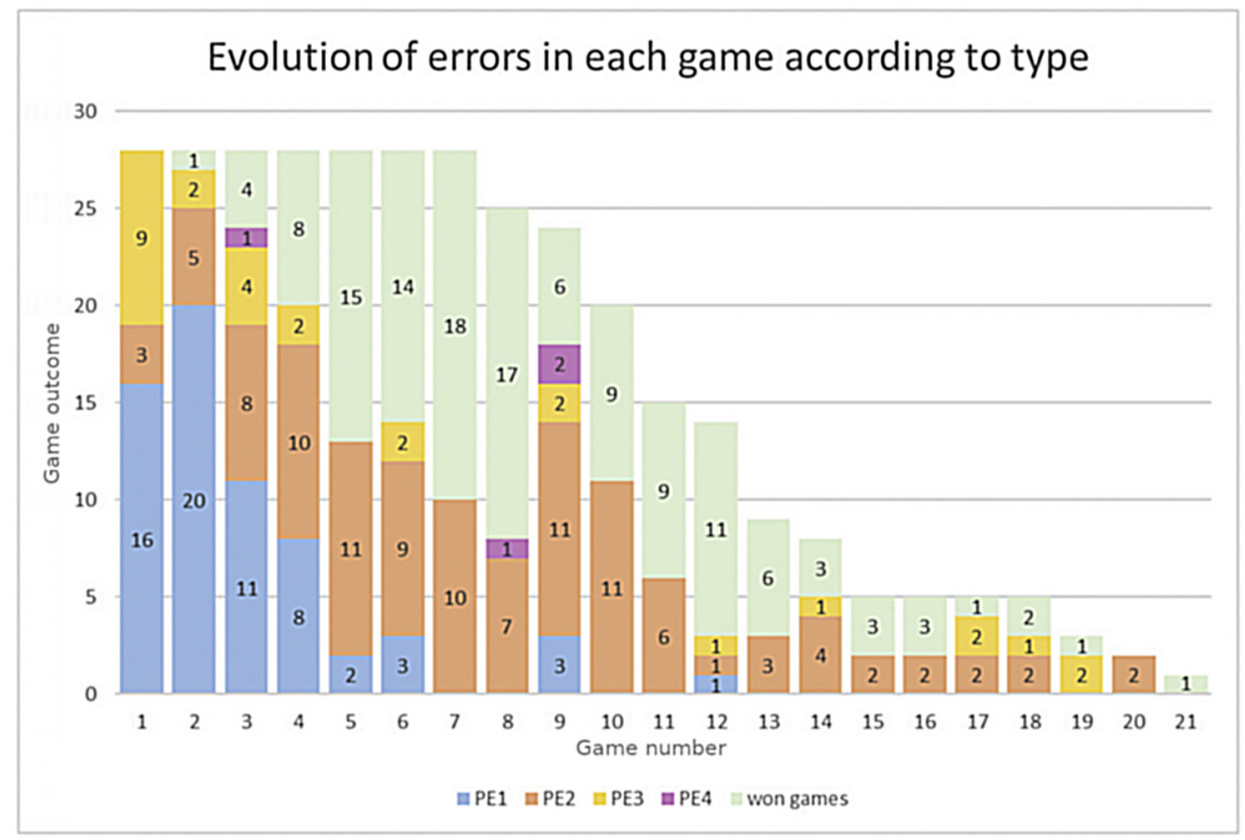

Figure 3 Evolution of errors in each game as per type.

first win, and the percentage of won games after the first win (see full list of variables in Table 4). The errors performed by players were recorded and classified into four categories:

- Type 1: errors attributable to the familiarization of the game technology itself, for instance, not turning on the pump when required.

- Type 2: errors attributable to a lack of basic perfusion knowledge that occur when the patient's variables are out of the normal range in noncritical situations.

- Type 3: errors related to communication skills, for instance, not answering to the surgeon.

- Type 4: errors caused by unsolved critical incidents that can happen even with a medium-high knowledge of the perfusion.

At the end of the session, students answered a questionnaire composed of the System Usability Scale (SUS) (Brooke, 1996) and other questions addressing specific aspects of the game usability: feedback, the error messages, suitability and correctness of the language, and immersion feeling (see Table 5). More questions were asked about particular aspects of the interface that are not relevant for this analysis. Students indicated their username in the questionnaire to match the game results with their answers.

\section{Results}

Table 4 describes the values of the variables taken into account. There were 337 games played; of which, 132 were won $(39.2 \%)$ and 205 were lost $(60.8 \%)$. Most of the games played were for task $1(85.76 \%)$.

The percentage of total type 1 errors made by students (PE1) is $31.22 \%$, type 2 (PE2) is $53.17 \%$, type 3 (PE3) is $13.66 \%$, and type 4 (PE4) is $1.95 \%$. Figure 3 shows the evolution of these errors throughout the session for all the students.

\begin{tabular}{llr} 
Table 5 & Answers of the Six Most Relevant Questions of the Questionnaire in a Scale of 1 (Strongly Disagree) to 5 (Strongly Agree) \\
\hline ID & Question & Mean (Min-Max) SD \\
\hline Q1 & The virtual environment was pleasant. & $4.43(3-5) \sigma=0,57$ \\
Q2 & The tone of the characters was suitable. & $4.36(3-5) \sigma=0.73$ \\
Q3 & I recognized the virtual environment. & $4.25(2-5) \sigma=0.75$ \\
Q4 & The game is useful for training and learning. & $4.11(1-5) \sigma=1.05$ \\
Q5 & I had a feeling of immersion. & $4.11(1-5) \sigma=0.99$ \\
Q6 & The game is easy. & $3.82(1-5) \sigma=1.05$ \\
\hline
\end{tabular}


Table 6 Analysis of Correlations of Gender, Age, Video Games Experience, and Perfusion Expertise in Relation to the Number of Games Needed Before the First Win

\begin{tabular}{lllr}
\hline Variables & Groups & Mean & Standard Deviation $(\sigma)$ \\
\hline Gender & Men & 6.1 & 22.77 \\
& Women & 4.11 & 5.28 \\
Age & $\geq 40$ years & 6.44 & 24.78 \\
Video game experience & $<40$ years & 4.05 & 4.83 \\
& No & 4.83 & 13.62 \\
Experience in perfusion & Yes & 4.75 & 2.25 \\
& No & 5.59 & 17.13 \\
\hline
\end{tabular}

The result of the SUS questionnaire was 72 . Table 5 contains the answers of the six main questions in a Likert scale of 1 (strongly disagree) to 5 (strongly agree).

Finally, Table 6 contains the results of the correlations between the number of games needed before the first win, and the gender, age, experience in video games, and experience in perfusion applying the t-student test.

\section{Discussion}

During the session, students played on average 10 games (NPSS $=10.46$ ), with a total average number of games (NPS) of 12 counting also the games played outside the session (during the week, at home). The average duration of each game (D) is approximately 5 minutes. It is higher for won games ( $\mathrm{DW} \approx 6.5$ minutes) because students play the whole virtual surgical procedure. These data are consequent with the design of the game in which the real duration of the perfusion has been scaled down to a shorter virtual temporal dimension. In addition, the percentage of games played after the first win, in relation to the total number of games played per student, is high (PPaft $=52.37 \%$ ), which suggests that they do not lose interest after the first win and continue to play to improve the score. In accordance with the motivational theory (Venkatesh \& Speier, 1999), this result may indicate that the main motivational factor was intrinsic and that the extrinsic motivation brought by game mechanics helped but was not determinant. These data also point at the positive individual's feelings about performing the target behavior. Moreover, some participants expressed their excitement about telling their children about this activity, showing that it was important to people they cared about. These two observations are consistent with the constructs of attitude toward behavior and subjective norm that are the basis of the theory of reasoned action (Davis, Bagozzi, \& Warshaw, 1989) to explain technology acceptance.

All students could win the game at some moment (minimum PWS $=9.52 \%$ ) However, it is not trivially easy: less than $50 \%$ of the games were won
$(\mathrm{PWS}=40.92 \%)$ and all students lost at least 1 game before the first win (minimum NPbef $=1$ ), needing on average more than 4 games (NPbef $=4.33$ ). This is consistent with the opinions of the students in question 6 $(\mathrm{Q} 6=3.82$ of 5$)$. This is an important preliminary finding because players engagement in a game is influenced by the difficulty curve (Aponte, Levieux, \& Natkin, 2009). Once the students have won for the first time, the percentage of won games increases (PWaft $=61.80 \%$ ), which indicates that students improved their performance along time because they got used to the technology and acquired knowledge. Indeed, the percentage of errors attributable to a lack of experience of the technology (PE1) is $31.22 \%$. Still, this type of error occurs mostly during the first games: the percentage of type 1 errors drops from $59.02 \%$ to $7.05 \%$ after the third game (see Figure 3). Errors caused by communication skills are low $(\mathrm{PE} 3=13.66 \%)$. This is partially explicable by the fact that the game is conductivist: questions are repeated, sometimes up to three times, and the dialog icon is made visible each time players have to express something. Thus, players have opportunities to express and answer. Students did not complain about the insistence of the dialogues and found the tone of the characters suitable, as suggested by the answers in question $2(\mathrm{Q} 2=4.36$ of 5). Type 4 errors are the lowest $(\mathrm{PE} 4=1.95 \%)$ because in this first session, most of the games played (85.76\%) were for task 1 (easy level).

Consistently with Dindar (Dindar, 2018), we found no correlation between gender and success in the game. On average, men needed more games than women to win for the first time (6.1 vs 4.11) probably because more women than men had some experience in perfusion (44\% vs $30 \%$ ).

On average, younger students got better results than older ones (4.05 vs 6.44), but the sample is too small to generalize any conclusion. However, the impression of the facilitators during the session was that older students felt more insecure at the beginning ("I'm bad using computers" was a generalized comment). They also expressed their happiness in winning more effusively. This may indicate that more help is needed at the beginning for older users. Besides, although data are insufficient to generalize 
any conclusion, the Virtual Perfusionist could have a side benefit on increasing students' confidence in playing.

There is almost no difference between gamers and nongamers (4.75 vs 4.83 ). This can be explained by the fact that even gamers did not devote a lot of time to play, and only 1 of them was a player of a 3D game. Indeed, this student got better results than the average, but this is not conclusive. In any case, the lack of experience in video games is not a handicap to train with this game.

Finally, as expected, students who had some experience in perfusion got better results than the others (3.63 vs 5.59, a trend of 0.008 ).

The game usability got a 72 SUS score more than the 68 threshold, but it can be improved because a score higher than 80 is recommendable (Brooke, 1996). The detailed questions about specific interactions of the game showed that one particular action (clamping) was found difficult. We have enhanced it. The answers to the questionnaire show that students clearly recognized the virtual environment $(\mathrm{Q} 3=4.25$ of 5$)$ and that they had a strong feeling of immersion (Q5 $=4.11$ of 5). Concerning satisfaction, participants liked the game $(\mathrm{Q} 1=4.43$ of 5$)$. This result is consistent with the observations performed during the sessions: students were very expressive and even shouted when they won for the first time. A repeated comment was "I have succeeded in my first perfusion," showing that they felt it almost as if it was a real surgery.

Students valued the game as a useful training tool $(\mathrm{Q} 4=4.11$ of 5$)$, some of them enthusiastically. The usefulness of the game and the transfer of knowledge to real skills were not measured. However, teachers expressed that after this session, students showed a better comprehension of the management of the CPB. Teachers and students referred to what happened in the game to illustrate or discuss some concepts. Teachers were very satisfied with the experience.

\section{Lessons Learned}

Some lessons were learned from this preliminary experience. First, developing the game was time and cost consuming. To make the effort worth, the game must have a prolonged use over time. For that, new tasks and situations need to be developed. Second, the learning curve must be smoothed through a tutorial task. Finally, although attendees were enthusiastic, we cannot be sure if the game would be equally praised, if used for assessment.

\section{Conclusions}

A 3D serious simulation game to train the CPB technique has been described. The game usability has been preliminary evaluated by 28 nurse perfusion students with encouraging results. Students were able to use it, they liked it, and thought that it is a good training tool, an opinion shared by perfusion teachers.

The next steps from these results are to integrate a tutorial task, other incidents, and more complex situations that could make it useful also for expert professionals. Further studies are also required to evaluate if the game improves students' learning outcomes and how it impacts on real-life skills.

All data used in this article and a demonstration video are available at the following server: https://www.cs.upc. edu/ dani/virtual_perfusionist.html.

\section{Supplementary Data}

Supplementary data to this article can be found online at https://doi.org/10.1016/j.ecns.2020.08.007.

\section{References}

Alsalemi, A., Tanaka, L., Ogino, M., Disi, M. A., Alhomsi, Y., Bensaali, F., ..., \& Alinier, G. (2020). A skills acquisition study on ECMOjo: A screen-based simulator for extracorporeal membrane oxygenation. Perfusion, 35(2), 110-116.

Aponte, M., Levieux, G., \& Natkin, S. (2009). Scaling the level of difficulty in single player video games. In Natkin, S., \& Dupire, J. (Eds.), Lecture Notes in Computer Science. (5709). Heidelberg: Springer, Berlin.

Bauernschmitt, R., Naujokat, E., Mehmanesh, H., Schulz, S., Vahl, C., Hagl, S., \& Lange, R. (1999). Mathematical modelling of extracorporeal circulation: Simulation of different perfusion regimens. Perfusion, 14(5), 321-330.

Bedwell, W., Pavlas, D., Heyne, K., Lazzara, E. H., \& Salas, E. (2012). Toward a taxonomy linking game attributes to learning: An empirical study. Simulation \& Gaming, 43(6), 729-760.

Brolhorst, J., Peterson, B., \& Holt, D. W. (2019). Flow awareness as a new safety device for cardiopulmonary bypass. The Journal of Extracorporeal Technology, 51(1), 20-25.

Brooke, J. (1996). SUS: A "quick and dirty" usability scale. In Jordan, P. W., Thomas, B., McClelland, I. L., \& Weerdmeester, B. A. (Eds.), Usability Evaluation in Industry (189-194). London: Taylor and Francis. Retrieved from https://www.usabilitest.com/system-usability-scale.

Cameron, J. L. (1997). William stewart halsted. Our surgical heritage. Annals of surgery, 225, 445-458.

Curtin, L. B., Finn, L. A., Czosnowski, Q. A., Whitman, C. B., \& Cawley, M. J. (2011). Computer-based simulation training to improve learning outcomes in mannequin-based simulation exercises. American Journal of Pharmaceutical Education, 75(6), 1-113.

Davis, F., Bagozzi, R., \& Warshaw, P. (1989). User acceptance of computer technology: A comparison of two theoretical models. Management Science, 35, 982-1003.

Dindar, M. (2018). An empirical study on gender, video game play, academic success and complex problem solving skills. Computers \& Education, 125, 39-52.

Ewertsson, M., Bagga-Gupta, S., \& Blomberg, K. (2017). Nurse Education in Practice, 27, 157-164.

Fischer, Q., Sbissa, Y., Nhan, P., Adjedj, J., Picard, F., Mignon, A., \& Varenne, O. (2018). Use of simulator-based teaching to improve medical 
students' knowledge and competencies: Randomized controlled trial. J Med Internet Res, 20(9), e261.

Gentry, S. V., Gauthier, A., L'Estrade Ehrstrom, B., Wortley, D., Lilienthal, A., Tudor Car, L., ..., \& Car, J. (2019). Serious gaming and gamification education in health professions: Systematic review. Journal of Medical Internet Research, 21(3), e12994.

Gomar, C., Mata, M. T., \& Pomar, J. L. (2012). Fisiopatología y técnicas de circulación extracorpórea. Ergon.

Gonzalez, L., \& Kardong-Edgren, S. (2017). Deliberate practice for mastery learning in nursing. Clinical Simulation in Nursing, 13(1), $10-14$.

Graafland, M., \& Schijven, M. (2018). How serious games will improve healthcare. In Rivas, H., \& Wac, K. (Eds.), Digital Health. Health Informatics. Cham: Springer.

Graafland, M., Schraagen, J. M., \& Schijven, M. P. (2012). Systematic review of serious games for medical education and surgical skills training. British Journal of Surgery, 99(10), 1322-1330.

Hicks, G. L., Gangemi, J., Angona, R. E., Ramphal, P. S., Feins, R. F., \& Fann, J. I. (2011). Cardiopulmonary bypass simulation at the boot camp. The Journal of Thoracic and Cardiovascular Surgery, 141(1), 284-292.

INACSL Standards Committee. (2016). INACSL standards of best practice: Simulation ${ }^{\mathrm{SM}}$ facilitation. Clinical Simulation in Nursing, 12(S), S16-S20.

Johnsen, H. M., Fossum, M., Vivekananda-Schmidt, A., Fruhling, A., \& Sletteb $\varnothing$, A. (2018). Nursing students' perceptions of a video-based serious game's educational value: A pilot study. Nurse Education Today, 62, 62-68.

Landsdowne, W., Machin, D., \& Grant, D. J. (2012). Development of the orpheus perfusion simulator for use in high-fidelity extracorporeal membrane oxygenation simulation. The Journal of Extra-Corporeal Technology, 44(4), 250-255.

Morris, R. W., \& Pybus, D. A. (2007). "Orpheus" cardiopulmonary bypass simulation system. The Journal of Extra-corporeal Technology, 39(4), 228-233.
Palanzo, D. A. (2005). Perfusion safety: Defining the problem. Perfusion, 20(4), 195-203.

Pront, L., Müller, A., Koschade, A., \& Hutton, A. (2018). Gaming in nursing education: A literature review. Nursing Education Perspectives, 39(1), 23-28.

Reedy, G. B. (2015). Using cognitive load theory to inform simulation. Clinical Simulation in Nursing, 11, 355-360.

Stammers, A. H., \& Mejak, B. L. (2001). An update on perfusion safety: Does the type of perfusion practice affect the rate of incidents related to cardiopulmonary bypass? Perfusion, 16, 189-198.

Steadman, R. H., Coates, W. C., Huang, Y. M., Matevosian, R., Larmon, B. R., McCullough, L., \& Ariel, D. (2006). Simulation-based training is superior to problem-based learning for the acquisition of critical assessment and management skills. Crit Care Med, 34(1), 151-157.

Venkatesh, V., \& Speier, C. (1999). Computer technology training in the workplace: A longitudinal investigation of the effect of mood. Organizational Behavior and Human Decision Processes, 79(1), 1-28.

Venkatesh, V., Thong, J. Y. L., \& Xu, X. (2016). Unified theory of acceptance and use of technology: A synthesis and the road ahead. Journal of the Association for Information Systems, 17(5), 328-376.

Wayne, D. B., Butter, J., Siddall, V. J., Fudala, M. J., Linquist, L. A., Feinglass, J., \& McGaghie, W. C. (2005). Simulation based training of internal medicine residents in advanced cardiac life support protocols: A randomized trial. Teaching and Learning in Medicine: An International Journal, 17(3), 202-208.

Zakhary, B. M., Kam, L. M., Kaufman, B. S., \& Felner, K. J. (2017). The utility of high-fidelity simulation for training critical care fellows in the management of extracorporeal membrane oxygenation emergencies: A randomized controlled trial. Critical Care Medicine, 45, 1367-1373.

Zhang, J., \& Walji, M. F. (2011). Turf: Toward a unified framework of EHR usability. Journal of Biomedical Informatics, 44, 1056-1067.

Zyda, M. (2005). From visual simulation to virtual reality to games. Computer, 38(9), 25-32. 


\section{Appendix}

Appendix A Variables and Parameters Taken Into Account in the Computational Model That Simulates the Physiological Behavior of the Patient Connected to the Heart-Lung Machine

\begin{tabular}{|c|c|c|c|c|c|c|}
\hline Variable type & \multicolumn{2}{|c|}{ Acronym } & \multicolumn{2}{|c|}{ Description } & \multicolumn{2}{|l|}{ Units } \\
\hline \multirow{9}{*}{$\begin{array}{l}\text { machine } \\
\text { variable }\end{array}$} & \multicolumn{2}{|l|}{ Qa } & \multicolumn{2}{|c|}{ Flow rate of the arterial pump } & \multicolumn{2}{|l|}{$\mathrm{L} / \mathrm{min}$} \\
\hline & \multicolumn{2}{|c|}{ Qcardio } & \multicolumn{2}{|c|}{ Flow rate of the cardioplegia pump } & \multicolumn{2}{|l|}{$\mathrm{L} / \mathrm{min}$} \\
\hline & \multicolumn{2}{|c|}{ Qvent } & \multicolumn{2}{|c|}{ Flow rate of the vent pump } & \multicolumn{2}{|l|}{$\mathrm{L} / \mathrm{min}$} \\
\hline & \multicolumn{2}{|c|}{ Qsuction } & \multicolumn{2}{|c|}{ Flow rate of the suction pump } & \multicolumn{2}{|l|}{$\mathrm{L} / \mathrm{min}$} \\
\hline & \multicolumn{2}{|c|}{ Fi02 } & \multicolumn{2}{|r|}{ Percentage of oxygen to the gas mixture of the oxygenator } & \multicolumn{2}{|l|}{$\%$} \\
\hline & \multicolumn{2}{|c|}{ Qgas } & \multicolumn{2}{|r|}{ Flow rate of the gas mixture of the oxygenator } & \multicolumn{2}{|l|}{$\mathrm{L} / \mathrm{min}$} \\
\hline & \multicolumn{2}{|l|}{$\mathrm{T}$} & Tem & perature of the heater-cooler unit, in the oxygenator circuit & ${ }^{\circ} \mathrm{C}$ & \\
\hline & Bloc & & Leve & lof blood in the venous blood reservoir & $\mathrm{mL}$ & \\
\hline & R_E & & Extr & acorporeal circulation circuit resistance & $\mathrm{mmHg} \cdot \min / \mathrm{L}$ & \\
\hline Patient & $\mathrm{HR}$ & & Hear & rt rate & Bpm & \\
\hline variable & $\mathrm{CO}$ & & Card & liac Output & $\mathrm{L} / \mathrm{min}$ & \\
\hline & MAP & & Pati & ent's mean arterial pressure & $\mathrm{mmHg}$ & \\
\hline & $\mathrm{Pa}$ & & Arte & rial line pressure in the circuit & $\mathrm{mmHg}$ & \\
\hline & CVP & & Pati & ent's central venous pressure & $\mathrm{mmHg}$ & \\
\hline & $\mathrm{Hb}$ & & Amo & unt of hemoglobin in the patient's blood & $\mathrm{g} / \mathrm{dL}$ & \\
\hline & $\mathrm{HCT}$ & & Perc & entage of hematocrit in the patient's blood & $\%$ & \\
\hline & HCT & & Perc & entage of hematocrit in the patient's blood & $\%$ & \\
\hline & $\eta \eta$ & & Bloo & d viscosity coefficient & $\mathrm{kg} /(\mathrm{s} \cdot \mathrm{m})$ & \\
\hline & SVR & & Patic & ent's systemic vascular resistance & $\begin{array}{l}\left(\text { dyn } \cdot s / \mathrm{cm}^{5}\right) / 80(w \\
\text { units })\end{array}$ & \\
\hline & Ta & & $\begin{array}{r}\text { Bloo } \\
\text { ci }\end{array}$ & $\begin{array}{l}\text { d temperature in the arterial line of the extracorporeal circula } \\
\text { ircuit }\end{array}$ & & \\
\hline & Tv & & $\begin{array}{r}\text { Bloo } \\
\text { ci }\end{array}$ & $\begin{array}{l}\text { d temperature in the venous line of the extracorporeal circula } \\
\text { ircuit }\end{array}$ & & \\
\hline & D02 & & Oxyg & gen delivery & $\mathrm{mlO}_{2} / \mathrm{min}$ & \\
\hline & V02 & & $0 x y 9$ & gen consumption & $\mathrm{mlO}_{2} / \mathrm{min}$ & \\
\hline & Sv0 & & Venc & ous oxygen saturation & $\%$ & \\
\hline & $\mathrm{SaO}$ & & Arte & rial oxygen saturation & $\%$ & \\
\hline & p02 & & Parti & ial pressure of arterial blood oxygen & $\mathrm{mmHg}$ & \\
\hline & $\mathrm{pCO}$ & & Part & ial pressure of arterial blood carbon dioxide & $\mathrm{mmHg}$ & \\
\hline & $\mathrm{pH}$ & & Pote & ential of hydrogen of the patient's blood & - & \\
\hline & ACT & & Acti & vated clotting time & $\mathrm{s}$ & \\
\hline & Vasc & adorDose & Vaso & dilator drug amount delivered & $\mathrm{mL}$ & \\
\hline & Vasc & trictorDose & Vaso & constrictor drug amount delivered & $\mathrm{mL}$ & \\
\hline & Hep & ose & Hep & arin amount delivered & $\mathrm{mL}$ & \\
\hline & Bloc & & Bloo & d amount delivered & $\mathrm{mL}$ & \\
\hline & Sert & & Seru & Im amount delivered & $\mathrm{mL}$ & \\
\hline & LVB & evel & Amo & unt of blood in the left ventricle cavity & $\mathrm{mL}$ & \\
\hline & CBlc & vel & Amo & unt of blood in the aortic root (or around cardiotomy) & $\mathrm{mL}$ & \\
\hline Parameter type & & Acronym & & Description & & Units \\
\hline Patient parame & ter & Gender & & Gender (woman or man) & & - \\
\hline & & Age & & Age & & years \\
\hline & & W & & Weight & & $\mathrm{Kg}$ \\
\hline & & $\mathrm{H}$ & & Height & & $\mathrm{cm}$ \\
\hline & & BSA & & Patient's body surface area & & $\mathrm{m}^{2}$ \\
\hline & & Initial_vo & lume & Initial blood volume of the patient & & $\mathrm{mL}$ \\
\hline Machine param & eter & ECC_volun & & Priming volume of the extracorporeal circulation circuit & & $\mathrm{mL}$ \\
\hline $\begin{array}{l}\text { Patient-machir } \\
\text { parameter }\end{array}$ & & Total_volı & & $\begin{array}{l}\text { Total blood volume when the patient is connected to the ex } \\
\text { circuit }\end{array}$ & orporeal circulation & $\mathrm{mL}$ \\
\hline
\end{tabular}

